\title{
JUURNAL_RU
}

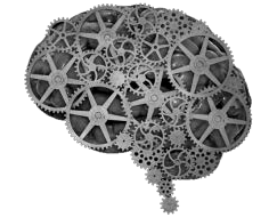

COMPANY GROUP "INTELLEKT"

\author{
${ }^{1}$ Масесе П.М., ${ }^{1,2}$ Мизина П.Г., ${ }^{2}$ Зилфикаров И.Н. \\ ${ }^{1}$ Российский университет дружбы народов \\ ${ }^{2}$ Всероссийский научно-исследовательский институт \\ лекарственных и ароматических растений \\ Москва, Россия
}

doi: 10.18411/lj2016-3-89

\section{Обоснование рационального состава комбинированного лекарственного фитосредства антимикробного и иммуностимулирующего действия}

Лекарственные растения являются неистощимым источникам эффективных и безопасных биологически активных веществ и служат базой для разработки новых антимикробных лекарственных средств, для которых быстрое развитие к ним лекарственной резистентности микроорганизмов не характерно [1]. Авторитетные эксперты ВОЗ считают, что около $75 \%$ всех больных целесообразно лечить только препаратами растительного происхождения (Т.П. Гарник, 2015) [2], так как они обладают рядом преимуществ, по сравнению с синтетическими субстанциями: мягкое терапевтическое действие, низкая токсичность, а также способность комплексно влиять на различные звенья патологического процесса и возможность длительного применения в различных возрастных группах [3].

Примерами таких лекарственных средств являются сухие экстракты эвкалимин - очищенная сумма фенолоальдегидов из побегов и листьев эвкалипта прутовидного (Eucalyptus viminalis Labill.) и эстифан - суммарный экстракт из травы эхинацеи пурпурной - (Echinacea purpurea L. Moench.). Эвкалимин обладает широким спектром антимикробной активности и оказывает бактериостатическое действие в отношении ряда лабораторных штаммов патогенных и условно-патогенных микроорганизмов, ингибируя рост 
грамположительных бактерий [4]. Эстифан оказывает иммуностимулирующее и противовоспалительное действие [5]. На основе эвкалимина ранее были разработаны жидкие и мягкие лекарственные формы (раствор 1\% спиртовой для наружного применения, гель, крем, суппозитории) [6], на основе эстифана таблетки для приема внутрь [7]. Учитывая широкий спектр фармакологического действия эвкалимина и эстифана, является целесообразным дальнейшее расширение ассортимента комплексных лекарственных фитопрепаратов на их основе, в частности, для лечения воспалительных заболеваний полости рта.

Цель работы - обосновать рациональный состав таблеток для рассасывания на основе фитоэкстрактов - эвкалимин и эстифан.

При проведении исследований были приготовлены семь экспериментальных составов таблетмассы, в которые были включены разрешенные для использования в фармацевтической технологии вспомогательные вещества: натрия стеарил фумарат (Ph. Eur., Sodium stearyl fumarate), кремния диоксид коллоидный (Ph. Eur., AEROSIL Pharma), декстрозы моногидрат (Ph. Eur., Dextrose monohydrate) (табл. 1).

Таблища 1

\begin{tabular}{|l|l|l|l|l|l|l|l|}
\hline \multicolumn{1}{|c|}{ Составы экспериментальных смесей для таблетирования } \\
\hline \multirow{3}{*}{ Наименование ингредиента } & \multicolumn{6}{l|}{ Количество, \% } \\
\cline { 2 - 9 } & Номера экспериентальных составов \\
\cline { 2 - 8 } & №1 & №2 & №3 & №4 & №5 & №6 & №7 \\
\hline Эвкалимин & 1,5 & 3,0 & 6,0 & 9,0 & 12,0 & 15,0 & 18,0 \\
\hline Эстифан & 1,5 & 3,0 & 6,0 & 9,0 & 12,0 & 15,0 & 18,0 \\
\hline Натрия стеарил фумарат & 0,5 & 0,5 & 0,7 & 1,00 & 0,9 & 1,0 & 1,50 \\
\hline Кремния диоксид коллоидный & 0,5 & 0,5 & 0,7 & 1,00 & 0,9 & 1,0 & 1,50 \\
\hline Декстроза моногидрат & 97,0 & 92,4 & 85,0 & 81,3 & 78,4 & 71,6 & 63,7 \\
\hline
\end{tabular}

Полученные смеси анализировали до прессования, определяя показатели сыпучесть, фракционный состав, прессуемость, и после таблетирования по показателям распадаемость, прочность на истирание и прочность на раздавливание. Анализируя экспериментальные составы для выбора оптимального из них, применили математическую функцию желательности Харрингтона (D). Обобщенная функция желательности удовлетворяет всем необходимым требованиям, предъявляемым к параметрам оптимизации. Шкала 
желательности Харрингтона - количественный, однозначный, единый, универсальный показатель качества объекта, как параметра оптимизации [8, 9].

Выбранные показатели служили переменными при расчете функции D1 до прессования, и D2 - после прессования, значения которых рассчитывали по формуле:

$\mathrm{D}=\sqrt[3]{\mathrm{d}_{1} \cdot \mathrm{d}_{2} \cdot \mathrm{d}_{3}}$, где

при расчете D1: d1 - сыпучесть, d2 - фракционный состав, d3 прессуемость;

при расчете D2: d1 - распадаемость, d2 - прочность на истирание, d3 прочность на раздавливание.

Полученные результаты представлены в табл. 2.

Таблица 2. Распределение показателей функции желательности Харрингтона для экспериментальных составов таблеток

\begin{tabular}{|c|c|c|c|c|c|c|c|c|}
\hline \multirow{2}{*}{$\begin{array}{l}\text { №№ } \\
\text { составов }\end{array}$} & \multicolumn{3}{|c|}{$\begin{array}{ll}\text { До } & \text { прессования } \\
\text { (таблетмасса) } & \\
\end{array}$} & \multirow{2}{*}{$D_{1}$} & \multicolumn{3}{|c|}{$\begin{array}{ll}\begin{array}{l}\text { После } \\
\text { (таблетки) }\end{array} & \text { прессования } \\
\end{array}$} & \multirow{2}{*}{$D_{2}$} \\
\hline & $d_{1}$ & $d_{2}$ & $d_{3}$ & & $d_{1}$ & $d_{2}$ & $d_{3}$ & \\
\hline 1 & 0,90 & 0,70 & 0,90 & 0,83 & 0,60 & 0,85 & 0,90 & 0,77 \\
\hline 2 & 0,70 & 0,80 & 0,70 & 0,73 & 0,65 & 0,65 & 0,75 & 0,68 \\
\hline 3 & 0,80 & 0,85 & 0,80 & 0,82 & 0,70 & 0,70 & 0,80 & 0,73 \\
\hline 4 & 0,90 & 0,95 & 0,95 & $\begin{array}{c}0,93 \\
\end{array}$ & 0,90 & $\mathbf{0 , 9 0}$ & 0,90 & 0,90 \\
\hline 5 & 0,55 & 0,80 & 0,60 & 0,64 & 0,65 & 0,50 & 0,50 & 0,55 \\
\hline 6 & 0,50 & 0,75 & 0,50 & 0,57 & 0,60 & 0,45 & 0,45 & 0,505 \\
\hline 7 & 0,35 & 0,70 & 0,50 & 0,50 & 0,50 & 0,45 & 0,40 & 0,45 \\
\hline
\end{tabular}

Если хотя бы одна частная желательность di равна 0 , то и функция Di = 0 . Это значит, что данный состав смеси не может быть применен, т. к. один из показателей не соответствует нормам. Если все показатели di равны 1, то и обобщенная функция Di = 1, а исследуемый состав признается оптимальным, так как комбинация показателей наилучшая [8].

При анализе полученных результатов установлено, что среди исследованных модельных смесей неудовлетворительных составов нет, так как значение D во всех случаях больше 0. Экспериментальный состав № 4 имеет значения близкие к $1(\mathrm{D}=0,9)$. Данный состав был признан оптимальным для создания таблеток и выбран для дальнейших исследований. 
Таким образом, анализ литературных данных, посвященных химическому составу и фармакологическим свойствам биологически активных субстанций растительного происхождения - эвкалимина и эстифана, позволяет считать обоснованным создание на их основе нового комбинированного лекарственного препарата антимикробного и противовоспалительного действия - таблеток для рассасывания. С применением математической функции желательности Харрингтона из модельного ряда нами выбран оптимальный состав, для которого технологические свойства таблетмассы и показатели качества готовых таблеток являются оптимальными и соответствуют нормативным значениям, предъявляемым к таблеткам для рассасывания. 


\section{Литература:}

1. Вичканова С.А. Лекарственные средства из растений. М., 2009. С. 347 370.

2. Гарник Т.П.[http://www.health-ua.org/archives/health/790.html дата обращения 01.02.2015

3. Бут Г. Преимущества назначения комплексных препаратов растительного происхождения для лечения заболеваний ЛОР-органов http:/www.healthua.org/archives/health/503.html

4. Вичканова С.А. Новые аспекты применения эвкалимина. //Вопросы биологической, медицинской и фармацевтической химии. 2012. №1 С. 214-220.

5. Крепкова Л.В., Бортникова В.В., Боровкова М.В., Сокольская Т.А. Доклиническое токсикологическое исследование фитопрепаратов из эхинацеи пурпурной травы. //Вопросы биологической медицинской и фармацевтической химии. 2012. №1. - С 178-184.

6. Семкина О. А. Разработка состава и технологии мягких лекарственных форм эвкалимина. Автореферат дисс.......канд. фарм. наук. М., 2005 г. 25 c.

7. Ашихмин Я. Новые перспективы применения препаратов на основе эхинацеи. //Врач, 2010, №1. С. 32-34.

8. Королева С.В. Практические аспекты использования функции желательности в медико-биологическом эксперименте. //Современные проблемы науки и образования. Электронный научный журнал 2011. №6.URL: http://www.science-education.ru/ru/article/view?id=5270 (дата обращения: 07.03.2016).

9. Грошовый Т.A., Маркова Е.В., Головкин В.А. Математическое планирование эксперимента в фармацевтической технологии. Киев:Вища школа, 1992. 185 с. 